\title{
Surface-associated properties of Streptococcus milleri group strains and their potential relation to pathogenesis
}

\author{
M. D. P. WILLCOX and K. W. KNOX
}

Institute of Dental Research, United Dental Hospital of Sydney, Chalmers Street, Surry Hills, NSW 2010. Australia

\begin{abstract}
Summary. Thirty strains from the Streptococcus milleri (anginosus) group (SMG) obtained from various sources were tested for a range of characters that could be associated with pathogenicity and the results were compared with those for type strains of $S$. sanguis, $S$. mutans and $S$. pyogenes. The SMG strains were heterogeneous in all tests. Most (18) belonged to one of the Lancefield groups with group $F$ predominating. Adherence of strains isolated from abscesses to buccal epithelial cells was greater than that of other strains $(p=0.033)$. Compared with strains of $S$. sanguis, SMG strains were generally not aggregated by human saliva. They differed from the type strain of $S$. pyogenes in their relative ability to bind fibrinogen and fibronectin; they were less effective in binding fibrinogen $(0 \cdot 33-4 \cdot 28 \% \mathrm{cf} .22 \%$ for $S$. pyogenes) and generally more effective in binding fibronectin $(0 \cdot 49-12 \cdot 37 \% \mathrm{cf} .0 \cdot 95 \%)$. Strains isolated from infections were statistically better at binding fibronectin than other strains $(p<0.001)$. The ability of strains to adhere to saliva-coated hydroxyapatite (SHA) varied 10 -fold, from $0 \cdot 16-16 \cdot 35 \%$. The amount of fibronectin bound by SMG strains correlated with their ability to adhere to SHA $(p<0.001)$. The hydrophobicity of the strains, as measured in the hexadecane partition assay, ranged from $0.0 \%$ to $99.0 \%$. Some strains carried both positive and negative cell-surface charges and some strains with a highly hydrophobic cell surface also possessed a relatively high cellsurface charge. A minority of strains possessed a net positive cell-surface charge. Neither hydrophobicity nor cell-surface charge was related to the capacity of strains to adhere to SHA. Strains of SMG co-aggregated weakly with strains of Veillonella parvula, $V$. dispar, Actinomyces viscosus and A. naeslundii.
\end{abstract}

\section{Introduction}

Strains of streptococci variously called Streptococcus milleri, $S$. intermedius, $S$. constellatus and $S$. anginosus have recently been classified together as $S$. anginosus (Coykendall et al., 1987). However, there is some degree of biochemical heterogeneity within the species, e.g., in the fermentation of lactose, mannitol and raffinose, and whether they are $\beta$-haemolytic (Ruoff, 1988). Knight and Shlaes (1988) have demonstrated genetic differences, and recent work has shown that there are at least 10 serotypes with many strains belonging to Lancefield groups A, C, F or G (Yakushiji et al., 1988). Because of the confusion in the nomenclature, some authors refer to the $S$. milleri group (SMG; Gossling, 1988), and this name is used in this study.

Received 3 Oct. 1989; accepted 10 Oct. 1989.
The prevalence of SMG at different sites on the human body indicates that it is probably a commensal (Ruoff, 1988). However, strains have been isolated from severe suppurative infections in many organs in the human body including the central nervous system (De Louvois, 1980) and the liver (Moore-Gillon et al., 1981), and they may be implicated in dental caries (Drucker and Green, 1978). Thus, in recent years it has been realised that SMG strains may be "unrecognised pathogens" (Ruoff, 1988).

Information on the pathogenic determinants of SMG strains is very limited (Poole and Wilson, 1976; Ruoff and Ferraro, 1987) but comparative studies on other bacteria draw attention to the importance of adhesion to surfaces, to tissue components and to other bacteria (co-aggregation) in this regard. Accordingly SMG strains were tested for their ability to adhere to saliva-coated hydroxy- 
apatite (Wyatt et al., 1987) and buccal epithelial cells (Handley et al., 1987), to bind fibrinogen (Whitnack et al., 1984) and fibronectin (Abraham et al., 1983; Babu and Dabbous, 1986; Hogg and Manning, 1989), and to co-aggregate with strains of Veillonella and Actinomyces (Cisar et al., 1979; Weerkamp and McBride, 1981). Hydrophobicity and surface charge may contribute to adhesion; therefore these properties were also investigated.

\section{Materials and methods}

\section{Bacterial strains}

The 30 strains of SMG available for study were obtained from several sources. Dr P. S. Handley (Department of Cell and Structural Biology, University of Manchester) supplied the type strains and Dr A. H. Rogers (Department of Dentistry, University of Adelaide, Australia) supplied strains B448 and 699B3. Two strains (MW8 and MS4) were freshly isolated from dental plaque. All these strains have been assigned to category 1 in table I.

Isolates associated with infections were provided by Dr J. Tappsell, Prince of Wales Hospital, Sydney (designated POW 1-5), Dr D. J. Groot-Obbink, Royal North Shore Hospital, Sydney (designated RNS2) and Dr K. Ruoff, Massachusetts General Hospital, Boston, USA (the remaining 15 strains). Isolates from infections were assigned to category 2 in table I and the remainder of the strains to category 3 .

The site of isolation of all the hospital and some of the other strains is given in table I. For comparative purposes, specific tests were also performed on $S$. mutans Ingbritt 175 and $S$. pyogenes NCTC 8198 (from our freeze-dried culture collection) and on $S$. sanguis LGR2 (provided by Dr P. S. Handley).

Co-aggregation studies were performed with the following strains from our freeze-dried collection: $V$. parvula NCTC 11745 and NCTC 10790; V. dispar NCTC 17748; V.atypica NCTC 17744; A.viscosus WVU626 and T14V; $A$. naeslundi NCTC $12104 ; A$. israeli WVU307; A. odontolyticus NCTC 9931; Rothia dentocariosa W853.

\section{Growth conditions}

Strains of streptococci were grown in Brain-Heart Infusion Broth (Difco) supplemented with yeast extract $0.3 \% \mathrm{w} / \mathrm{v}$ (Difco) $(\mathrm{BHI}+\mathrm{Y})$ at $37^{\circ} \mathrm{C}$ for $18 \mathrm{~h}$ in an anaerobic jar. For measuring cellular adhesion and surface charge, broth cultures were supplemented with ${ }^{3} \mathrm{H}$-thymidine $2 \mu \mathrm{Ci} / \mathrm{ml}$. Cultures were washed three times in buffer (Tris- $\mathrm{MgSO}_{4} ; 0.01 \mathrm{M}$ Tris- $\mathrm{HCl}, \mathrm{pH} 7.00$, $+0.01 \mathrm{M} \mathrm{MgSO}_{4}$ ) and re-suspended to an $\mathrm{OD}_{660}$ of $1 \cdot 00 \pm 0.02$. All strains were grown on Colombia Agar (Difco) supplemented with sheep's blood $5 \% \mathrm{v} / \mathrm{v}$ for biochemical characterisation.
For co-aggregation, the Actinomyces strains were grown in $\mathrm{BHI}+\mathrm{Y}$ for $18 \mathrm{~h}$ at $37^{\circ} \mathrm{C}$, whereas Veillonella strains were grown in tryptone-lactate broth (Rogosa, 1964) containing tryptone $5 \mathrm{~g} / \mathrm{L}$, yeast extract $3 \mathrm{~g} / \mathrm{L}$, sodium thioglycollate $0.75 \mathrm{~g} / \mathrm{L}$, Tween $801 \mathrm{ml} / \mathrm{L}$ and sodium lactate $(70 \% \mathrm{w} / \mathrm{w}) 21 \mathrm{ml} / \mathrm{L}$ for $48 \mathrm{~h}$ at $37^{\circ} \mathrm{C}$. All cells were washed in Tris- $\mathrm{MgSO}_{4}$ buffer and finally re-suspended in buffer to an $\mathrm{OD}_{660}$ of $1 \cdot 0$.

\section{Biochemical characterisation and Lancefield grouping}

The biochemical characters of the strains were assessed with the API 20 Strep test kits (API System, Vercieu, France). This system differentiates between three biotypes of $S$. milleri. Biotype I does not hydrolyse aesculin or ferment lactose or starch; biotype II produces the opposite reactions; biotype III produces $\alpha$-galactosidase and ferments mannitol and raffinose. The Lancefield grouping was done with the Streptex latex agglutination kit (Wellcome Diagnostics, Hertford).

\section{Adhesion to buccal epithelial cells}

Buccal epithelial cells (BEC) were harvested by scraping the buccal mucosa of volunteers with wooden tongue depressors and re-suspending the cells in Tris$\mathrm{MgSO}_{4}$. The BEC were washed twice in the buffer and finally re-suspended to an $\mathrm{OD}_{550}$ of $0 \cdot 2-(1-2) \times 10^{6}$ BEC $/ \mathrm{ml}$. BEC $(0 \cdot 1 \mathrm{ml})$ and washed bacterial cells $(0 \cdot 1 \mathrm{ml}$; see above) were added to flat-bottomed wells in a microtitration plate and incubated for $2 \mathrm{~h}$ at $37^{\circ} \mathrm{C}$ with shaking. After incubation, the cells were harvested with a Titertek cell harvester (Flow Laboratories, Australia) on to polycarbonate filters of $3 \cdot 0-\mu \mathrm{m}$ pore size (Nucleopore Corp., Pleasanton, USA). Unattached bacteria were washed through the filter pores with buffer, the larger BEC being retained on the filter. The filters were removed and the radioactive emission was counted in a Beckman LS 9000 scintillation counter. Controls of bacteria alone were also filtered and any counts obtained from these controls were subtracted from the counts of the samples with BEC. Each strain was tested in quadruplicate on two occasions.

\section{Aggregation of cells by whole saliva}

A spectrophotometric assay (Ericson et al., 1975; Wyatt and Handley, 1987) was employed to assess the ability of whole human saliva to aggregate the bacterial cells. Unstimulated saliva was centrifuged at $10000 \mathrm{~g}$ for $20 \mathrm{~min}$ to remove cells. Triplicate $0.5-\mathrm{ml}$ samples of the clarified saliva were then mixed with equal volumes of bacterial suspension. The $\mathrm{OD}_{660}$ was measured immediately and at 30-min intervals for $2 \mathrm{~h}$. Controls of bacterial cells with no saliva were also tested. All experiments were repeated; this gave six measurements for each test strain. 


\section{Binding of fibrinogen or fibronectin}

Purified rat fibrinogen and fibronectin, kindly donated by Dr N. Hunter (Institute of Dental Research, Sydney) were labelled with ${ }^{125} \mathrm{I}$ according to the method of Markwell (1982). A concentration of fibrinogen or fibronectin of $1 \mu \mathrm{g} / \mathrm{ml}$ was chosen to enable a direct comparison with published data (Babu et al., 1983) and because $S$. mutans Ingbritt has been shown to bind fibrinogen specifically at this concentration (unpublished results).

Bacteria were grown for $18 \mathrm{~h}$ at $37^{\circ} \mathrm{C}$ in $\mathrm{BHI}+\mathrm{Y}$, washed three times in phosphate-buffered saline (PBS; $\mathrm{NaCl} 8 \mathrm{~g} / \mathrm{L}, \mathrm{KCl} 0.2 \mathrm{~g} / \mathrm{L}, \mathrm{Na}_{2} \mathrm{HPO}_{4} .12 \mathrm{H}_{2} \mathrm{O} 2.9 \mathrm{~g} / \mathrm{L}$, $\mathrm{KH}_{2} \mathrm{PO}_{4} \quad 0.2 \mathrm{~g} / \mathrm{L}$ ) containing bovine serum albumin (BSA) $1 \% \mathrm{v} / \mathrm{v}$. The cells were finally re-suspended in PBS + BSA containing Tween $200.05 \% \mathrm{v} / \mathrm{v}$. The bacterial cell suspension $(0.5 \mathrm{ml})$ was added to a microcentrifuge tube followed by $1 \mu \mathrm{g}$ of ${ }^{125} \mathrm{I}$-fibrinogen or ${ }^{125} \mathrm{I}$ fibronectin. The tubes were incubated at $37^{\circ} \mathrm{C}$ for $30 \mathrm{~min}$ and centrifuged for $10 \mathrm{~min}$ at $5000 \mathrm{~g}$; the cells were washed once with PBS+BSA + Tween 20 and again centrifuged. The supernate was removed and the amount of radiolabel associated with the bacterial pellet and the supernate from both centrifugations was measured. The degree of binding was expressed as the amount of radiolabel associated with the pellet divided by the total amount of radiolabel added. Control tubes containing fibrinogen or fibronectin only were also run. Any radioactivity associated with the control tubes was subtracted from the test scores.

\section{Adhesion to saliva-coated hydroxyapatite ( $S H A$ )}

The method used was that of Wyatt et al. (1987). Freshly collected whole human saliva was centrifuged at $10000 \mathrm{~g}$ for $20 \mathrm{~min}$ and $0.5 \mathrm{ml}$ was added to $20 \mathrm{mg}$ of spheroidal hydroxyapatite (BDH). The saliva was allowed to coat the hydroxyapatite for $1 \mathrm{~h}$ at $22^{\circ} \mathrm{C}$ on a rotary shaking device. The hydroxyapatite was then washed twice in buffer and $0.5 \mathrm{ml}$ of bacterial cell suspension was added. The SHA and bacteria were incubated on a rotary device for $2 \mathrm{~h}$ at $22^{\circ} \mathrm{C}$. The SHA was then washed three times in buffer and finally the amount of radioactivity associated with the SHA was measured in a Beckman LS 9000 scintillation counter. Each strain was tested in triplicate on two occasions.

\section{Hydrophobicity assay}

Relative hydrophobicities were assessed by the hexadecane partition procedure (Rosenberg et al., 1980). Briefly, $0.86 \mathrm{ml}$ of bacterial suspension (see above) was vortex mixed with $0.14 \mathrm{ml}$ of hexadecane (BDH) for $2 \mathrm{~min}$. The percentage reduction in the $\mathrm{OD}_{660}$ of the aqueous phase from triplicate samples was determined and all experiments were repeated.

\section{Estimation of cell-surface charge}

The relative surface charge of the bacteria was measured by the method of Jenkinson and Carter (1988). Disposable 1-ml plastic syringes (Terumo Corp., Tokyo, Japan) were plugged with cotton wool and a slurry of DEAE-Sepharose CL-6B or CM-Sepharose CL-6B was packed into the syringe to a height of $50 \mathrm{~mm} .{ }^{3} \mathrm{H}$ thymidine-labelled cells $(50 \mu \mathrm{l})$, in Tris- $\mathrm{MgSO}_{4}$ buffer, were added to the top of the syringe and eluted with $10 \mathrm{ml}$ of buffer. The exchange resin was then removed from the syringe and the radioactivity of the resin and of the eluate was counted in a liquid scintillation counter. The affinity of the bacteria for the column was expressed as the ratio of the radioactivity in the column (c) and in the corresponding eluate (e). The higher the c/e value, the greater the affinity for the exchange resin and thus the greater the corresponding charge on the bacterial cell surface.

\section{Co-aggregation assay}

A standard visual assay for co-aggregation was used (Cisar et al., 1979). Equal volumes (0.1 ml) of streptococci and either Veillonella spp. or actinomycetes were mixed on a vortex mixer for $30 \mathrm{~s}$, left to stand at room temperature overnight and mixed again, and the coaggregation score was then read. Control tubes were set up which contained $0.1 \mathrm{ml}$ of bacterial suspension and $0.1 \mathrm{ml}$ of buffer only. Any co-aggregation score in the control tubes was deducted from the test score. The coaggregation was scored as follows: $0=$ no visible aggregates; $1=$ small uniform aggregates in suspension; $2=$ definite aggregates that did not immediately settle; $3=$ large aggregates that partly settled; $4=$ large aggregates that settled immediately.

The effect of lactose on the co-aggregation was measured by its addition to a final concentration of $0.06 \mathrm{M}$ before vortex mixing for $30 \mathrm{~s}$. The effect of heat on coaggregation was assessed by heating one member of a coaggregation pair at $80^{\circ} \mathrm{C}$ for $30 \mathrm{~min}$ and then mixing with its unheated partner.

\section{Statistical analysis}

Spearman's correlation coefficient (Sokal and Rohlf, 1981) was used to determine statistically significant correlations between data. The Mann-Whitney U-test was used to determine statistically significant differences between data sets.

\section{Results}

\section{Biochemical characterisation and Lancefield grouping}

On the basis of their biochemical profiles, $83 \%$ of the strains were assigned to one of the three biotypes, the majority (17) belonging to biotype II 
(table I). This table also shows results for lactose and mannitol fermentation as these may be important in the biochemical speciation of the strains. Fewer than half the strains were $\beta$-haemolytic (11), although this character was shown by all the strains isolated from the throat (3) and sputum (4). The majority of strains could be classified into Lancefield groups $\mathrm{A}, \mathrm{C}, \mathrm{F}$ or $\mathrm{G}$ (table I) with group $\mathrm{F}$ predominating (11).

Adhesion of strains to BEC, salivary aggregation and binding of fibrinogen

These three properties are compared in table II.

Table I. Site of isolation, biochemical characterisation and Lancefield groups of SMG strains

\begin{tabular}{|c|c|c|c|c|c|c|}
\hline Strain & $\begin{array}{l}\text { Site of } \\
\text { isolation }\end{array}$ & Biotype* & Lac & Mann & Haem & Group \\
\hline $\begin{array}{c}\text { Category } 1 \\
\text { NCTC } \\
11325\end{array}$ & NK & I/II & - & - & - & - \\
\hline $\begin{array}{c}\text { NCTC } \\
11324\end{array}$ & NK & II & + & - & - & - \\
\hline $\begin{array}{l}\text { NCTC } \\
10713\end{array}$ & Throat & III & + & - & + & G \\
\hline $\begin{array}{c}\text { NCTC } \\
10708\end{array}$ & Dental abscess & II & + & - & - & - \\
\hline $\begin{array}{l}\text { NCTC } \\
10709\end{array}$ & Dental abscess & II & + & - & - & - \\
\hline B448 & NK & II & + & - & - & - \\
\hline 699B3 & NK & II & + & - & - & F \\
\hline MW8 & Dental plaque & II & + & - & - & $\mathrm{F}$ \\
\hline MS 4 & Dental plaque & II & + & - & - & $\mathrm{F}$ \\
\hline \multicolumn{7}{|l|}{ Category 2} \\
\hline POW 1 & Appendiceal abscess & II & + & - & + & $\mathrm{C}$ \\
\hline POW 2 & Brain abscess & $\mathrm{II} / \mathrm{III}$ & + & + & - & - \\
\hline POW 3 & Cerebral abscess & II/III & + & + & - & - \\
\hline 631 & Abdominal abscess & II & + & - & - & - \\
\hline 618 & Facial abscess & II & + & - & - & $\mathrm{F}$ \\
\hline 687 & Axillary abscess & III & + & + & - & $\mathrm{F}$ \\
\hline C117221-1 & Perirectal abscess & II & + & - & + & $\mathrm{C}$ \\
\hline \multicolumn{7}{|l|}{ Category 3} \\
\hline 573 & Wound & II & + & - & - & $\mathrm{F}$ \\
\hline 525 & Wound & $\mathrm{II} / \mathrm{I}$ & - & - & - & - \\
\hline F6 & Wound & I & - & - & + & $\mathrm{F}$ \\
\hline A1784 & Throat & I & - & - & + & A \\
\hline $\mathrm{C} 5$ & Throat & II & + & - & + & C \\
\hline NAG 18 & Throat & I & - & - & + & - \\
\hline F4 & Sputum & III & + & + & + & $\mathrm{F}$ \\
\hline G14 & Sputum & II & + & - & + & G \\
\hline $\mathrm{G} 23$ & Sputum & II & + & - & + & G \\
\hline NAG4 & Sputum & II & + & - & + & - \\
\hline POW 4 & Bile & II & + & - & - & $\mathrm{F}$ \\
\hline POW 5 & Blood & I/II & + & - & - & $\mathrm{F}$ \\
\hline RNS 2 & Ear & III & + & - & - & - \\
\hline 481 & Urine & III & + & + & - & $\mathrm{F}$ \\
\hline
\end{tabular}

$\mathrm{NK}=$ Not $\quad$ known $; \quad$ Haem $=\beta$-haemolysis $; \quad$ Lac =lactose $\quad$ fermentation Mann $=$ mannitol fermentation.

* Biotype from API 20 Strep test kits.

$\dagger$ Lancefield grouping; $-=$ not groupable. 
Table II. Ability of strains of SMG to adhere to BEC, to aggregate with whole human saliva and to bind fibrinogen

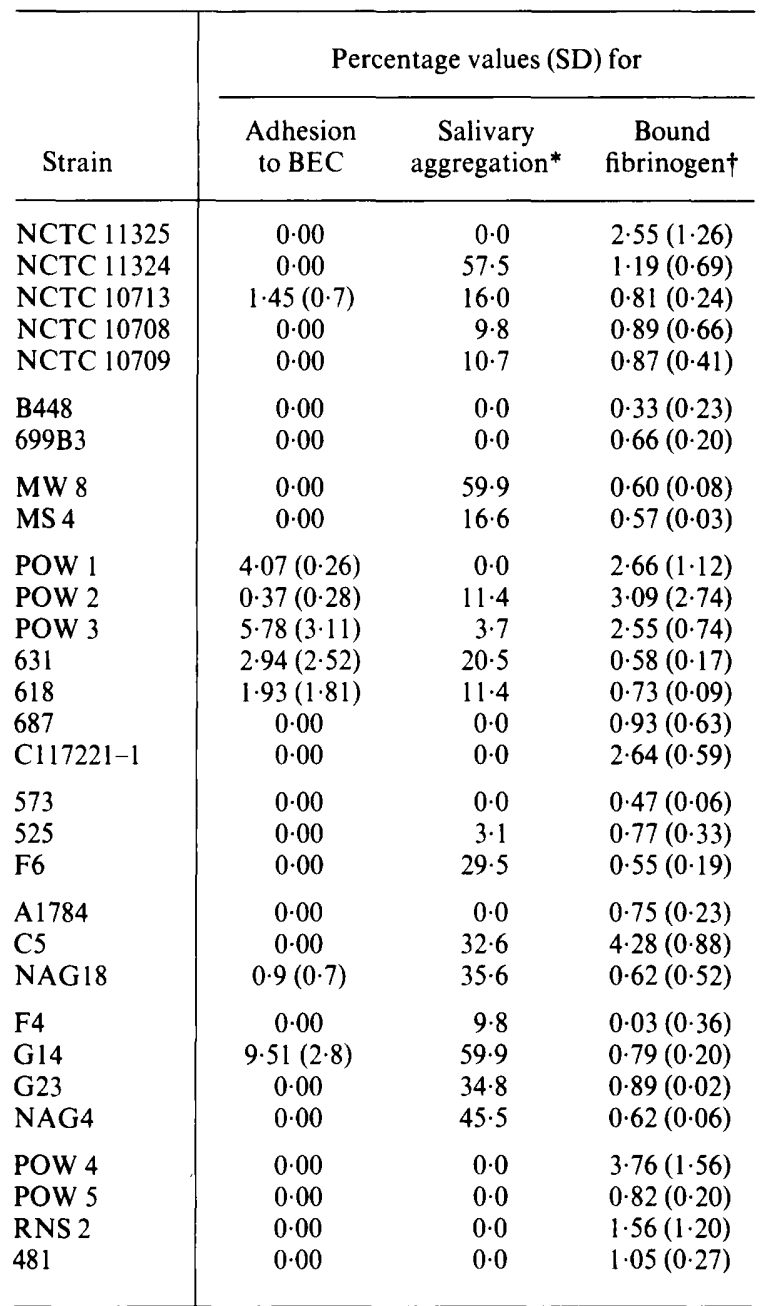

* Percentage aggregation is reduction in OD relative to $S$. sanguis LGR2 (0.224 SD 0.022).

$\dagger$ Bound fibrinogen expressed as a percentage of the added fibrinogen $(1 \mu \mathrm{g})$.

The majority of SMG strains $(73 \%)$ and also the type strains of the other species did not bind to BEC. Of the strains that gave adhesion values > $1 \%$, four were from a series of seven recent isolates from abscesses (category 2); one other isolate gave a lower value. Analysis of the results by the MannWhitney U-test showed that there was a statistically significant difference between the ability of category 2 strains and the other strains (categories 1 and 3) to adhere to BEC $(p=0.033)$. Grouped amongst the category 1 strains were two type strains (NCTC 10708 and NCTC 10709) that were originally isolated from dental abscesses (Mejare and Edwardsson, 1975) but which had been repeatedly subcultured, possibly producing alterations in their character.

The results of tests for aggregation with saliva are expressed as a percentage of the value for S. sanguis LGR2 (0.224 SD 0.022). This organism was chosen as a reference standard because its aggregation by parotid saliva is known to be moderately good (Wyatt and Handley, 1987). The majority of strains were aggregated poorly $(<20 \%)$ or not at all; only three gave values $>50 \%$.

The amount of fibrinogen bound by the SMG strains is expressed as a percentage of the added fibrinogen $(1 \mu \mathrm{g})$. Values ranged from $0.33 \%$ (strain B448) to $4 \cdot 28 \%$ (strain C5); seven strains bound $>2 \%$ of the fibrinogen. These values are in the same range as those for the strains of $S$. sanguis $(2.08 \%$ SD 2.33$)$ and $S$. mutans $(1.99 \%$ SD 0.23$)$ but considerably less than that for $S$. pyogenes $(22 \%$ SD 0.49).

\section{Binding of fibronectin and adhesion to $\mathrm{SHA}$}

The results of the fibronectin assay are given in fig. $1 \mathrm{~A}$ and to allow comparison with the fibrinogen assay they are also expressed as a percentage of the added protein $(1 \mu \mathrm{g})$ that was bound. Nearly half of the strains bound $>2 \%$ of the fibronectin, with six values $>5 \%$. The strains of $S$. mutans, $S$. sanguis and $S$. pyogenes produced low levels of binding to fibronectin $(1.3,1.8$ and $1.0 \%$ respectively).

The results of adhesion to SHA (fig. 1B) show a 10 -fold variation, from $0 \cdot 16 \%$ for strain B448 to $16.35 \%$ for strain POW 1. Adhesion values for half of the strains (15) were $>2 \%$ and for six were $>6 \%$. The two strains from dental plaque, MW 8 and MS 4, gave values of $4.87 \%$ SD 0.81 and $1.29 \%$ SD 0.21 respectively, which were between the values for the other two plaque strains, S. mutans Ingbritt $175(1.48 \%$ SD 0.42$)$ and $S$. sanguis LGR2 $(20.49 \%$ SD $2.47 \%)$. None of the SMG strains was able to adhere to SHA as well as the strain of S. sanguis.

The results for the strains shown in figs $1 \mathrm{~A}$ and B were compared statistically by Spearman's correlation coefficient. This showed that there was a highly significant correlation $(p<0.001)$ between the ability of a strain to adhere to SHA and its ability to bind fibronectin; strains that adhered in high numbers to SHA were likely to bind high amounts of fibronectin.

The results for fibronectin binding have been grouped (fig. 2) so that a comparison can be made between isolates of categories 1,2 and 3 (table I). Analysis of these results by the Mann-Whitney Utest showed that the binding of fibronectin by 

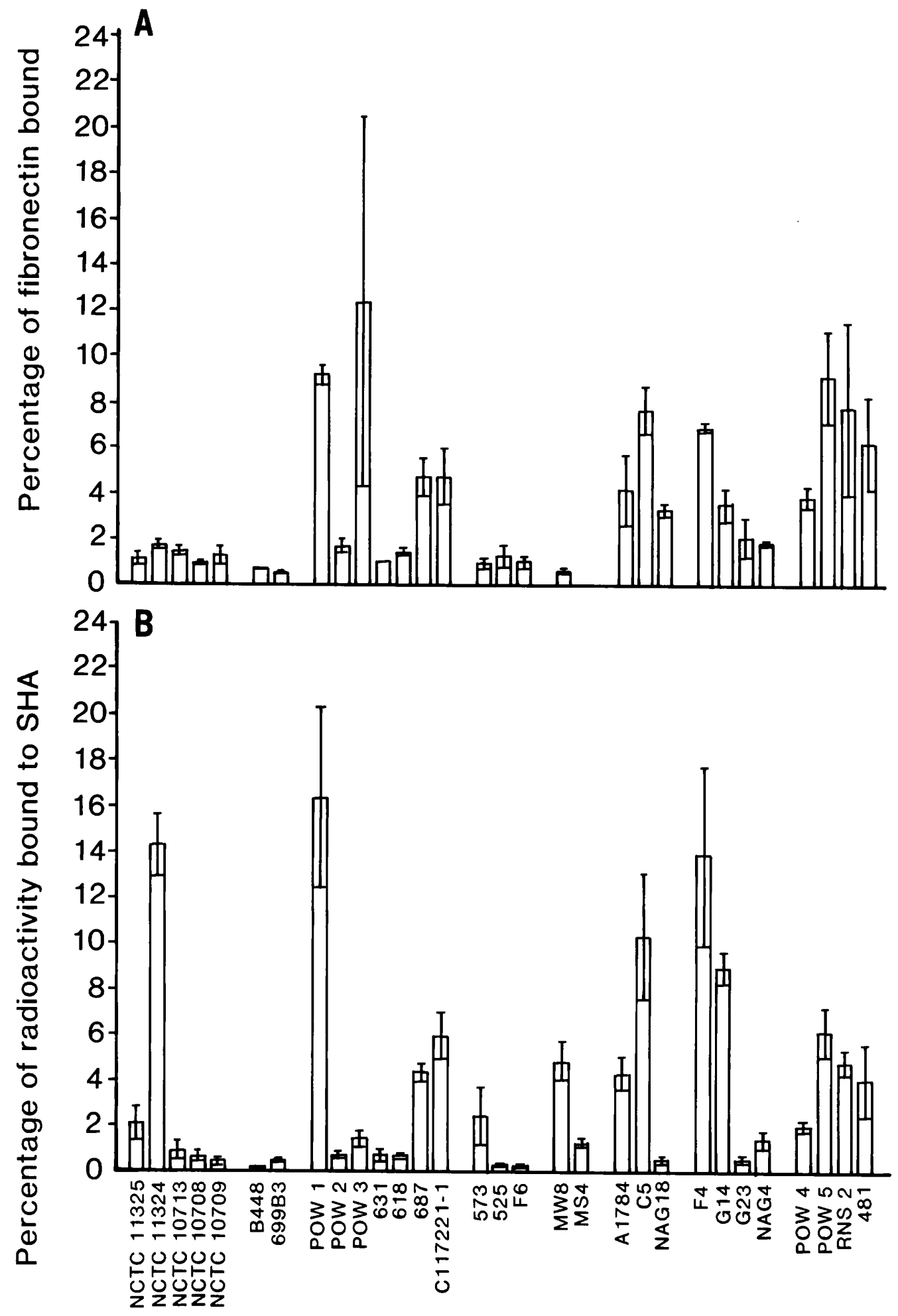

Strain no.

Fig. 1. Binding of SMG to fibronectin (A) and adhesion to saliva-coated hydroxyapatite (B). A statistically significant correlation $(\mathrm{p}<0.001$, Spearman's correlation coefficient) was shown between these two parameters. 


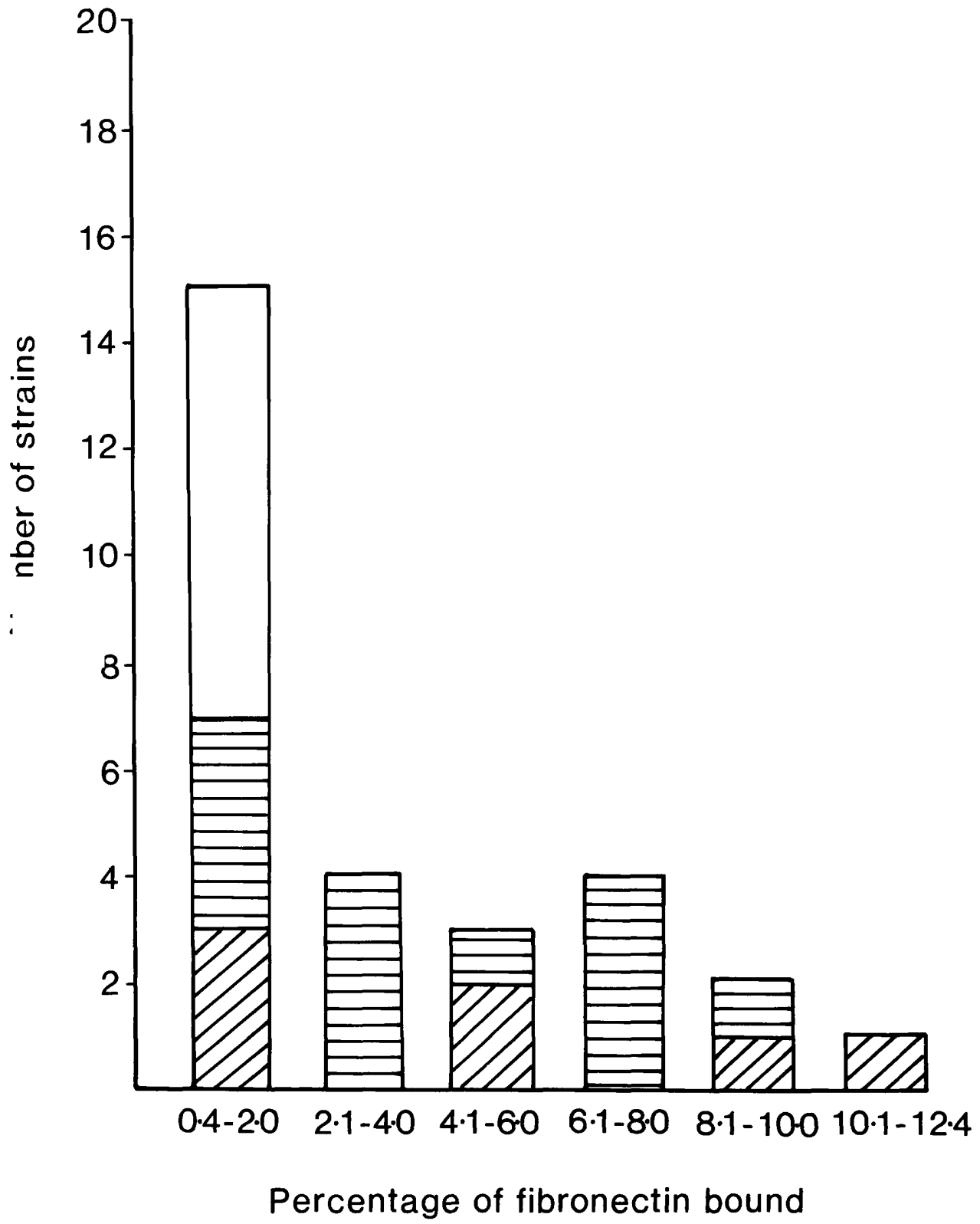

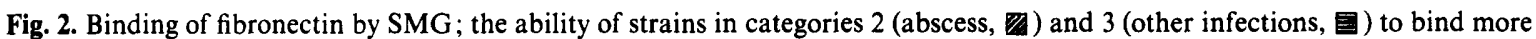
fibronectin than strains in category 1 (others, $\square$ ) was significant $(\mathrm{p}<0.001)$. Results presented in fig. 1 were divided into the following groups : $0 \cdot 4-2 \cdot 0 \%, 2 \cdot 1-4 \cdot 0 \%, 4 \cdot 1-6 \cdot 0 \%, 6 \cdot 1-8 \cdot 0 \%, 8 \cdot 1-10 \cdot 0 \%$ and $10 \cdot 1-12 \cdot 4 \%$.

strains in categories 2 and 3 combined (collectively called infection isolates) was significantly greater than for category 1 strains $(\mathrm{p}<0.001)$.

\section{Hydrophobicity and surface charge}

Strains differed widely in their hydrophobicities as measured by partitioning with hexadecane (table III). Only six strains of SMG were highly hydrophobic ( $>80 \%$ ) and three strains moderately hydrophobic $(50-79 \%) ; 13$ strains gave a low value $(10-49 \%)$ and eight strains gave a very low value $(<10 \%)$. The hydrophobicities of the test strains of S. sanguis LGR2, S. mutans Ingbritt 175 and S. pyogenes NCTC 8198 were $70.3 \%$ SD $1 \cdot 2,47 \cdot 1 \%$ SD 2.4 and $91.6 \%$ SD 3.8 respectively. 
Table III. Percentage hydrophobicity and cell-surface charge associated with SMG strains

\begin{tabular}{|c|c|c|c|c|c|}
\hline \multirow[b]{2}{*}{ Strain } & \multicolumn{2}{|c|}{ Hydrophobicity* } & \multicolumn{3}{|c|}{ Surface charge $\dagger$} \\
\hline & $\begin{array}{l}\text { Percentage } \\
\text { (SD) }\end{array}$ & Category & DEAE & $\mathrm{CM}$ & Net \\
\hline NCTC 11325 & $6 \cdot 2(1 \cdot 6)$ & Very low & $1 \cdot 40$ & 1.63 & +0.24 \\
\hline NCTC 11324 & $35 \cdot 3(3.9)$ & Low & $1 \cdot 56$ & $2 \cdot 36$ & +0.80 \\
\hline NCTC 10713 & $85 \cdot 2(1 \cdot 8)$ & High & 1.02 & $0 \cdot 20$ & -0.82 \\
\hline NCTC 10708 & $3 \cdot 2(3 \cdot 0)$ & Very low & 1.00 & 0.01 & -0.99 \\
\hline NCTC 10709 & $1 \cdot 2(1 \cdot 4)$ & Very low & $2 \cdot 14$ & 0.01 & $-2 \cdot 13$ \\
\hline B448 & $4 \cdot 6(2 \cdot 8)$ & Very low & $2 \cdot 10$ & $0 \cdot 88$ & $-1 \cdot 22$ \\
\hline 699B3 & $3 \cdot 2(4 \cdot 5)$ & Very low & $0 \cdot 69$ & 0.00 & -0.69 \\
\hline MW 8 & $99 \cdot 0(1 \cdot 5)$ & High & 0.89 & $0 \cdot 65$ & -0.24 \\
\hline MS 4 & $26 \cdot 7(4 \cdot 5)$ & Low & 0.93 & $0 \cdot 37$ & -0.56 \\
\hline POW 1 & $12 \cdot 1(5 \cdot 8)$ & Low & 1.62 & 0.62 & $-1 \cdot 00$ \\
\hline POW 2 & $33.0(3.8)$ & Low & 0.23 & $0 \cdot 10$ & $-0 \cdot 13$ \\
\hline POW 3 & $49 \cdot 0(2 \cdot 9)$ & Low & $1 \cdot 40$ & 0.03 & $-1 \cdot 37$ \\
\hline 631 & $45 \cdot 7(16 \cdot 4)$ & Low & 0.44 & 0.08 & $-0 \cdot 36$ \\
\hline 618 & $11 \cdot 1(2 \cdot 9)$ & Low & $1 \cdot 55$ & 0.34 & $-1 \cdot 21$ \\
\hline 687 & $95.8(1.2)$ & High & 3.04 & $0 \cdot 25$ & $-2 \cdot 79$ \\
\hline C117221-1 & $78 \cdot 4(6 \cdot 8)$ & Medium & $0 \cdot 60$ & 0.63 & +0.03 \\
\hline 573 & $11 \cdot 8(2 \cdot 7)$ & Low & $0 \cdot 86$ & 0.05 & -0.81 \\
\hline 525 & 0.00 & Very low & 0.82 & 0.60 & -0.22 \\
\hline F6 & $5 \cdot 6(4 \cdot 7)$ & Very low & $2 \cdot 39$ & $0 \cdot 25$ & $-2 \cdot 14$ \\
\hline A 1784 & $90 \cdot 7(2 \cdot 5)$ & High & $1 \cdot 39$ & 0.53 & -0.86 \\
\hline $\mathrm{C} 5$ & $93 \cdot 4(3 \cdot 2)$ & High & 1.98 & 1.65 & -0.33 \\
\hline NAG 18 & $29 \cdot 7(9 \cdot 3)$ & Low & $1 \cdot 38$ & $0 \cdot 16$ & $-1 \cdot 22$ \\
\hline F4 & $48 \cdot 8(12 \cdot 5)$ & Low & 3.53 & $0 \cdot 34$ & $-3 \cdot 19$ \\
\hline G14 & $59 \cdot 1(11.9)$ & Medium & $1 \cdot 07$ & 0.62 & -0.45 \\
\hline G23 & $41 \cdot 8(4.9)$ & Low & $0 \cdot 56$ & 0.30 & -0.26 \\
\hline NAG4 & $47 \cdot 0(12.9)$ & Low & $1 \cdot 11$ & $0 \cdot 88$ & -0.23 \\
\hline POW 4 & $35 \cdot 4(1 \cdot 7)$ & Low & $1 \cdot 53$ & $0 \cdot 12$ & -1.41 \\
\hline POW 5 & $9 \cdot 1(1 \cdot 7)$ & Very low & 0.74 & $0 \cdot 15$ & -0.59 \\
\hline RNS 2 & $80 \cdot 2(0 \cdot 7)$ & High & $1 \cdot 04$ & $0 \cdot 12$ & -0.92 \\
\hline & $64 \cdot 7(5 \cdot 0)$ & Medium & 0.42 & $0 \cdot 22$ & -0.20 \\
\hline
\end{tabular}

\footnotetext{
* Percentage hydrophobicity as measured in the hexadecane partition assay: $\mathrm{High}=80-99 \%$; Medium $=50-79 \%$; Low $=10-49 \%$; Very low $=0-9 \%$.

+ Surface charge: $\mathrm{DEAE}=$ negative cell surface, $\mathrm{CM}=$ positive cell surface (see Materials and methods); Net charge $=\mathrm{CM}-\mathrm{DEAE}$.
}

There was wide variation in the surface charge carried by the different strains (table III). Most strains possessed the expected net negative charge, as did the test strains of $S$. sanguis LGR2 (-0.69), $S$. mutans Ingbritt $175(-0.91)$ and $S$. pyogenes NCTC $8198(-1 \cdot 28)$. However, two strains, NCTC 11324 and NCTC 11325, possessed a significant net positive charge.

\section{Co-aggregation between SMG strains and other oral genera}

Each of the strains was tested for its ability to coaggregate with members of the genera Veillonella,
Actinomyces and Rothia. None co-aggregated with $V$. parvula NCTC 17745, V. atypica NCTC 17744 , $R$. dentocariosa W853 or A. odontolyticus NCTC 9931 and only one strain (525) co-aggregated with $A$. israeli WVU 307. The results obtained with $V$. parvula NCTC 10790, V. dispar NCTC 17748, A. viscosus WVU 626 and T14V, and $A$. naeslundi NCTC 12104 are given in table IV.

Lactose had no effect on any of the co-aggregation partnerships. Within the Veillonella-SMG pairs, heating the Veillonella strains eliminated all coaggregating ability, whereas heating the SMG strains that co-aggregated with Veillonella had no effect on co-aggregation. Within the Actinomyces- 
Table IV. Co-aggregation scores between SMG strains and Veillonella spp. and actinomycetes

\begin{tabular}{|c|c|c|c|c|c|c|}
\hline \multirow{3}{*}{$\begin{array}{c}\text { Strain } \\
\text { no. }^{*}\end{array}$} & \multicolumn{6}{|c|}{ Co-aggregation scores $\uparrow$ with } \\
\hline & \multirow{2}{*}{$\begin{array}{c}\text { V. parvula } \\
\text { NCTC } \\
10790\end{array}$} & \multirow{2}{*}{$\begin{array}{l}\text { V.dispar } \\
\text { NCTC } \\
17748\end{array}$} & \multicolumn{2}{|c|}{ A. viscosus } & \multirow{2}{*}{$\begin{array}{l}\text { A. naeslundi } \\
\text { NCTC } \\
12104\end{array}$} & \multirow{2}{*}{$\begin{array}{l}\text { A. israeli } \\
\text { WVU307 }\end{array}$} \\
\hline & & & WVU626 & $\mathrm{T} 14 \mathrm{~V}$ & & \\
\hline NCTC 11325 & - & - & $3^{\mathrm{M}}{ }_{\mathrm{A}}$ & - & - & - \\
\hline NCTC 11324 & $1_{v}$ & - & - & - & - & $2 \mathrm{~A}_{\mathrm{A}}$ \\
\hline B448 & - & $4 v$ & - & - & - & - \\
\hline MW 8 & - & $4 \mathrm{v}$ & $3_{\mathrm{A}}$ & - & $\bar{y}$ & - \\
\hline MS 4 & - & $3 \mathrm{v}$ & $3_{\mathrm{A}}$ & - & $2^{\mathrm{M}}{ }_{\mathrm{A}}$ & - \\
\hline POW 2 & $2 \mathrm{v}$ & - & - & - & - & - \\
\hline POW 3 & $2 \mathrm{v}$ & - & - & - & - & - \\
\hline 618 & - & - & $2_{\mathrm{A}}$ & - & - & - \\
\hline 573 & - & - & $3^{\mathrm{M}}{ }_{\mathrm{A}}$ & $2^{\mathrm{M}}{ }_{\mathrm{A}}$ & 1 & - \\
\hline NAG 18 & - & $3 v$ & $2_{A}$ & - & - & - \\
\hline POW 4 & - & $4 v$ & - & - & 2 & - \\
\hline
\end{tabular}

* No other strains of SMG were able to co-aggregate with the Veillonella strains or the actinomycetes.

$\dagger$ See Materials and methods.

$\mathrm{A}, \mathrm{V}, \mathrm{M}=$ Heating the actinomycete $(\mathrm{A})$, or Veillonella $(\mathrm{V})$, or $S$. milleri $(\mathrm{M})$ strain eliminated co-aggregation.

SMG pairs, most of the actinomycetes lost their ability to co-aggregate when heated (table IV) and some of the SMG strains were also susceptible to heating.

\section{Discussion}

The results of these studies provide further evidence of the heterogeneity of strains in the SMG. Based on physiological characters, $83 \%$ could be classified into one of the three biotypes, with biotype II predominating. There was no relationship between the source of a strain and its biotype, although it was more common for isolates from throat or sputum to be $\beta$-haemolytic. However, this may be just a simple reflection of the isolation procedures in hospital laboratories.

Lancefield serological classification of streptococci has proved particularly valuable in identifying pathogens. However, in the case of the SMG, our studies, and those of others, have shown that the strains that can be classified may belong to one of several groups, A, C, F or G, with group F predominating (Drucker and Lee, 1983; KilpperBalz et al., 1984). Strains that could not be so classified $-40 \%$ in this study-may belong to one or other of the 10 serotypes that have been described recently (Yakushiji et al., 1988).
In contrast to the range of studies on the physiological and serological characters of SMG, scant attention has been paid to those characters of potential importance with respect to pathogenicity. Adhesion to surfaces and the related ability to bind mammalian protein are given particular emphasis in this regard; accordingly, such studies were the prime concern in this investigation.

The first indication of a potential association between pathogenicity and surface characters came from the results of tests for adhesion to BEC, in which recent isolates from abscesses possessed a significantly greater ability to adhere than did other strains. The results for the abscess strains were similar to those for $S$. salivarius (unpublished observations), which is preferentially associated with epithelial surfaces (Sklavounou and Germaine, 1980). However, SMG are rarely cultured from the cheek (Mejare and Edwardsson, 1975; Michalek and McGhee, 1982) so that the lack of adhesion of many strains was not unexpected.

The ability of an organism to bind salivary proteins or glycoproteins is another important ecological factor (Gibbons, 1984). When the reaction is with components in solution, aggregation occurs which could lead to clearance of organisms from the mouth (Williams and Gibbons, 1975; Mandel, 1976); where the reaction is with compo- 
nents adsorbed to the tooth surfaces, plaque formation is enhanced (Gibbons, 1984). Ability to adhere to SHA frequently correlates with the presence of organisms in plaque (Gibbons and van Houte, 1975) and the generally low level of adhesion of SMG to SHA observed in this and a previous study (Willcox et al., 1985) correlates with their low levels in plaque. The nature of the adhesins for SHA on the cell surface of SMG strains has not been elucidated but may be associated with fimbriae, which were demonstrated recently on the surface of two strains of SMG (Willcox and Drucker, 1989). Correlation between adhesion to SHA and aggregation by saliva has been found with some oral streptococci (Ericson et al., 1983). However, the results from the present study do not support such a simple correlation. In view of the more recent work on the binding of salivary components to SHA, a degree of lack of correlation may be expected; for example, the component inducing aggregation may not be absorbed to SHA and adhesion may depend on a conformational change in the adsorbed protein (Gibbons, 1989).

Co-aggregation between different species is considered to be important in oral microbial ecology, enabling organisms that attach poorly to the tooth or BEC to colonise these surfaces by attaching to other bacteria that do adhere well. Relevant examples are $S$. sanguis- $A$. viscosus (Cisar et al., 1979), S. salivarius-Veillonella (Weerkamp and McBride, 1981), S. mutans-Veillonella (McBride and van der Hoeven, 1981) and SMG-actinomycetes (Kolenbrander and Williams, 1983; Willcox and Drucker, 1989). A more detailed study of the SMG has shown that co-aggregation with actinomycetes is not a common phenomenon and that few strains co-aggregate with Veillonella spp. The data support the proposal that the SMG strains are able to co-aggregate with actinomycetes by both lectin-carbohydrate and protein-protein interactions. In regard to the co-aggregation with Veillonella spp., these organisms appear to possess a protein on their cell surface that interacts with a carbohydrate on the surface of the SMG strains.

Further evidence of differences in the surface characters of the SMG strains comes from studies on their ability to bind two important mammalian proteins, fibrinogen and fibronectin. It has been proposed that the ability of strains of $S$. pyogenes to bind fibrinogen enables them to escape the host defence mechanisms (Whitnack et al., 1984) and the strain of $S$. pyogenes used in the current study did bind fibrinogen very effectively $(22 \%$ of the added protein). In contrast only seven SMG strains bound $>2 \%$ of the fibrinogen. However, it may be more valid to compare the results with those for the $S$. sanguis and S.mutans strains, for which the values also approximated $2 \%$. It can be calculated that, even at this level of binding, there would be c. $10^{2}$ molecules of fibrinogen per bacterial cell.

The ability to bind fibronectin may contribute to pathogenicity as this protein is found on the surface of many mammalian cells. Some reports have suggested that bacteria coated with fibronectin are more readily opsonised by polymorphonuclear leucocytes, although this is not the case with group B streptococci (Yang et al., 1988). The numbers of strains that bound $>10^{2}$ molecules of fibronectin per cell were similar to those that bound $10^{2}$ molecules of fibrinogen per cell. Those strains that had been isolated recently from infections (categories 2 and 3 ) bound fibronectin to a significantly greater extent than other strains (category 1), a result that is consistent with the proposal that such binding can contribute to pathogenicity.

There was a statistically significant correlation between the amount of fibronectin bound and the level of adhesion to SHA. Similar observations have been made with strains of $S$. mutans (Babu and Dabbous, 1986) and S. sanguis (Hogg and Manning, 1989) suggesting that the adhesion of these organisms to a salivary pellicle is enhanced by the presence of fibronectin in the pellicle.

On the basis of a wide range of studies, the observed differences in binding ability for the different SMG strains can be assumed to be due to differences in surface structures and components, particularly protein and, to a lesser extent, lipoteichoic acid (Gibbons, 1989). Proteins generally provide the specificity for adhesion and a qualitative examination of extractable surface proteins indicates that there are major differences between the SMG strains (unpublished observations). Hydrophobicity and surface charge may also play an important role in adhesion; therefore these properties were also examined. Furthermore, Absolom (1988) stated that the more hydrophobic the bacterial cell the more likely it is to be phagocytosed; thus cells with a low hydrophobicity value may also be able to evade the host defence mechanisms. The strains of SMG displayed a wide range of hydrophobicity values but there were no correlations between either hydrophobicity and source of strains or hydrophobicity and adhesion to SHA. The latter observation is in agreement with other studies on strains of $S$. sanguis (Wyatt et al., 1987) and $S$. salivarius (Handley et al., 1987).

The adhesion to SHA did not correlate with surface charge, although other oral streptococci have shown such a relationship (Reynolds and 
Wong, 1983; Jenkinson and Carter, 1988). The negative groups on the cell surface did not counteract adhesion, which would be expected if electrostatic repulsion forces were important in this process (Stenstrom, 1989). It was noted that strains with a high cell-surface hydrophobicity were also capable of possessing a relatively high cell-surface charge. This may indicate the presence of localised regions of charge on the cell surface that interact specifically with the charged groups on the Sepharose. Alternatively, the ability to possess both a hydrophobic cell surface and negative cell-surface charge may indicate that similar molecules such as lipoteichoic acid are responsible. Additionally, cellsurface proteins may undergo conformational changes, dependent on their environment. Different regions are exposed and thus a cell may be hydrophobic and have a charged cell surface. Localisation of charged groups may also explain why some strains carry a relatively high negative charge and a high positive charge on their cell surface.

\section{REFERENCES}

Abraham S N, Beachey E H, Simpson W A 1983 Adherence of Streptococcus pyogenes, Escherichia coli and Pseudomonas aeruginosa to fibronectin-coated and uncoated epithelial cells. Infection and Immunity 41 : 1261-1268.

Absolom D R 1988 The role of bacterial hydrophobicity in infection: bacterial adhesion and phagocytic ingestion. Canadian Journal of Microbiology 34 : 287-298.

Babu J P, Dabbous M K 1986 Interaction of salivary fibronectin with oral streptococci. Journal of Dental Research 65: 10941100.

Babu J P, Simpson W A, Courtney H S, Beachey E H 1983 Interaction of human plasma fibronectin with cariogenic and non-cariogenic oral streptococci. Infection and Immunity 41: $162-168$.

Cisar J O, Kolenbrander P E, McIntire F C 1979 Specificity of coaggregation reactions between human oral streptococci and strains of Actinomyces viscosus or Actinomycesnaeslundii. Infection and Immunity 24: 742-752.

Coykendall A L, Wesbecher P M, Gustafson K B 1987 "Streptococcus milleri", Streptococcus constellatus and Streptococcus intermedius are later synonyms of Streptococcus anginosus. International Journal of Systematic Bacteriology 37: 222-228.

de Louvois J 1980 Bacteriological examination of pus from abscesses of the central nervous system. Journal of Clinical Pathology 33: 66-71.

Drucker D B, Green R M 1978 The relative cariogenicities of Streptococcus milleri and other viridans group streptococci in gnotobiotic hooded rats. Archives of Oral Biology 23: 183-187.

Drucker D B, Lee S M 1983 Possible heterogeneity of Streptococcus milleri determined by DNA and mol \% (guanine plus cytosine) measurement and physiological characterisation. Microbios 38: 151-157.

Ericson T, Olsson J, Bowen W, Ciardi J, Rundegren J 1983
This study has demonstrated the heterogeneity of strains of SMG in the in-vitro assays used to test their pathological properties and it would appear that different strains may have different means of causing disease and evading host defences. For example, strains isolated from abscesses adhered to BEC much more effectively than other strains. Similarly, the ability of strains isolated from infections to bind more fibronectin than other strains may contribute to pathogenicity. A statistically significant correlation between the ability to bind fibronectin and the level of adhesion to SHA has been shown, suggesting that fibronectin is an important adhesin for these bacteria. The large number of strains available for the present study allowed for the selection of appropriate strains for further more detailed study into pathogenic mechanisms of the SMG.

This work was supported by a Program Grant from the National Health and Medical Research Council of Australia.

Effect of purified human salivary agglutinin on the adsorption of $S$. mutans to hydroxyapatite. In: ten Cate J. M. et al. (eds) Bacterial adhesion and preventative dentistry. IRL Press, Oxford, pp 63-71.

Ericson T, Pruit K, Wedel H 1975 The reaction of salivary substances with bacteria. Journal of Oral Pathology 4: 307323.

Gibbons R J 1984 Adherent interactions which may affect microbial ecology in the mouth. Journal of Dental Research 63: $378-385$.

Gibbons R J 1989 Bacterial adhesion to oral tissues: a model for infectious diseases. Journal of Dental Research 68: 750-760.

Gibbons R J, van Houte J 1975 Bacterial adherence in oral microbial ecology. Annual Review of Microbiology 29: 1944.

Gossling J 1988 Occurrence and pathogenicity of the Streptococcus milleri group. Reviews of Infectious Diseases 10: 257-285.

Handley P S, Harty D W S, Wyatt J E, Brown C R, Doran J P, Gibbs A C C 1987 A comparison of the adhesion, coaggregation and cell-surface hydrophobicity properties of fibrillar and fimbriate strains of Streptococcus salivarius. Journal of General Microbiology 133: 3207-3217.

Hogg S D, Manning J E 1989 Inhibition of adhesion of viridans streptococci to fibronectin coated hydroxyapatite beads by lipoteichoic acid. Journal of Applied Bacteriology 65 : 483489.

Jenkinson H F, Carter D A 1988 Cell surface mutants of Streptococcus sanguis with altered adherence properties. Oral Microbiology and Immunology 3: 53-57.

Kilpper-Balz R, Williams B L, Lutticken R, Schleifer K H 1984 Relatedness of "Streptococcus milleri" with Streptococcus anginosus and Streptococcus constellatus. Systematic and Applied Microbiology 5: 494-500.

Knight R G, Shlaes D M 1988 Physiological characteristics and deoxyribonucleic acid relatedness of Streptococcus intermedius strains. International Journal of Systematic Bacteriology 38: $19-24$. 
Kolenbrander P E, Williams B L 1983 Prevalence of viridans streptococci exhibiting lactose-inhibitable coaggregation with oral actinomycetes. Infection and Immunity 41 : 449452.

Mandel I D 1976 Non-immunologic aspects of caries resistance. Journal of Dental Research 55: 22-31.

Markwell M A 1982 A new solid-state reagent to iodinate proteins. I. Conditions for the efficient labeling of antiserum. Analytical Biochemistry 125: 427-432.

McBride B C, van der Hoeven J S 1981 Role of interbacterial adherence in colonization of the oral cavities of gnotobiotic rats infected with Streptococcus mutans and Veillonella alcalescens. Infection and Immunity 33 : 467-472.

Mejare B, Edwardsson S 1975 Streptococcus milleri (Guthof); an indigenous organism of the human oral cavity. Archives of Oral Biology 20 : 757-762.

Michalek S M, McGhee J R 1982 Oral streptococci with emphasis on Streptococcus mutans. In: McGhee J R et al. (eds) Dental microbiology. Harper and Row, Philadelphia, pp 679-690.

Moore-Gillon J C, Eykyn S J, Phillips I 1981 Microbiology of pyogenic liver abscess. British Medical Journal 283: 819821.

Poole P M, Wilson G 1976 Infection with minute-colonyforming $\beta$-haemolytic streptococci. Journal of Clinical Pathology 29: 740-745.

Reynolds E C, Wong A 1983 The effect of adsorbed protein on hydroxyapatite zeta potential and Streptococcus mutans adherence. Infection and Immunity 39: 1285-1290.

Rogosa M 1964 The genus Veillonella. I. General cultural, ecological and biochemical considerations. Journal of Bacteriology 87: 162-170.

Rosenberg M, Gutnick D, Rosenberg E 1980 Adherence of bacteria to hydrocarbons: a simple method for measuring cell-surface hydrophobicity. FEMS Microbiology Letters 9: 29-33.

Ruoff K L 1988 Streptococcus anginosus (Streptococcus milleri): the unrecognized pathogen. Clinical Microbiology Reviews 1: 102-108.

Ruoff K L, Ferraro M J 1987 Hydrolytic enzymes of "Streptococcus milleri”. Journal of Clinical Microbiology 25: 1645-1647.

Sklavounou A, Germaine G R 1980 Adherence of oral streptococci to keratinized and non-keratinized human oral epithelial cells. Infection and Immunity 27: 686-689.

Sokal R R, Rohlf F J 1981 Biometry: the principles and practice of statistics in biomedical research, 2nd edn. W. H. Freeman and Co., San Francisco, pp 372-387.

Stenstrom T A 1989 Bacterial hydrophobicity, an overall parameter for the measurement of adhesion potential to soil particles. Applied and Environmental Microbiology 55: 142 147.

Weerkamp A H, McBride B C 1981 Identification of a Streptococcus salivarius cell wall component mediating coaggregation with Veillonella alcalescens V1, Infection and Immunity 32: 723-730.

Willcox M D P, Drucker D B, Hillier V F, Green R M 1985 Relationship of adhesion in vitro and cariogenicity of oral Streptococcus species in germ-free rats. Archives of Oral Biology 30: 635-639.

Willcox M D P, Drucker D B 1989 Surface structures, coaggregation and adherence phenomena of Streptococcus oralis and related species. Microbios 59: 19-29.

Williams R C, Gibbons R J 1975 Inhibition of streptococcal attachment to receptors on human buccal epithelial cells by antigenically similar salivary components. Infection and Immunity 11: 711-718.

Whitnack E, Dale J B, Beachey E H 1984 Common protective antigens of group A streptococcal $\mathbf{M}$ proteins masked by fibrinogen. Journal of Experimental Medicine 159: 12011212.

Wyatt J E, Handley P S 1987 Aggregation of Streptococcus sanguis biotypes I and II by parotid saliva: a comparison between peritrichously fibrillar and tufted strains. Microbios 51: 113-123.

Wyatt J E, Hesketh L M, Handley P S 1987 Lack of correlation between fibrils, hydrophobicity and adhesion for strains of Streptococcus sanguis biotypes I and II. Microbios 50: 7-15.

Yakushiji T, Konagawa R, Oda M, Inoue M 1988 Serological variation in oral Streptococcus milleri. Journal of Medical Microbiology 27: 145-151.

Yang K D, Augustine N H, Gonzalez L A, Bohnsack J F, Hill H R 1988 Effects of fibronectin on the interaction of polymorphonuclear leukocytes with unopsonised and antibody-opsonised bacteria. Journal of Infectious Diseases 158 : 823-830. 